\title{
Can hazardous waste supply chain 'hotspots' be identified using an input-output framework?
}

Christa Jensen Court, MRI Global and Regional Research Institute, West Virginia University, 886 Chestnut Ridge Rd, Morgantown, WV 26505, United States;

Christa.Jensen@mail.wvu.edu; 1 304-293-3998

Max Munday*, Cardiff Business School, Cardiff University, Colum Drive, Cardiff CF10

3EU, UK; mundaymc@cf.ac.uk; 00442920875089

Annette Roberts, Cardiff Business School, Cardiff University, Colum Drive, Cardiff CF10

3EU, UK; robertsa1@cf.ac.uk; 00442920875058

Karen Turner, School of Management \& Languages, Heriot-Watt University, Edinburgh, EH14 4AS, United Kingdom; k.turner@hw.ac.uk; 00441314513978

* Corresponding author: Max Munday,

\section{Acknowledgements}

This paper draws on earlier research funded by the UK Economic and Social Research Council (Climate Change Leadership Fellowship, ESRC Grant Reference: RES-066-27-0029). We are also grateful to the UK Environment Agency for the provision of data on hazardous wastes.

\begin{abstract}
The paper examines a method to attribute hazardous waste streams to regional production and consumption activity, and to connect these same waste streams through to different management options. We argue that a method using an input-output framework provides useful intelligence for decision makers seeking to connect elements of the management of the hazardous waste hierarchy to production and to different patterns and types of final consumption (of which domestic household consumption is one). This paper extends application of conventional demand driven input-output attribution methods to identify hazardous waste 'hotspots' in the supply chains of different final consumption goods and consumption groups. Using a regional case study to exposit the framework and its use, we find that domestic government final consumption of public administration production indirectly drives hazardous waste generation that goes to landfill, particularly in the domestic construction and sanitary services sectors, but also in the manufacture of wood products.
\end{abstract}


Keywords: Decision support systems; Input-output tables; Hazardous waste management; Supply chain management

\section{Highlights:}

- The paper presents a method to attribute hazardous waste streams to regional production and consumption activity, and to connect these same waste streams through to different hazardous waste management options.

- The paper is set in the context of a tightening regulatory framework around hazardous waste. The methods adopted provide information for business decision makers and policy makers working to connect elements of the management of the hazardous waste hierarchy first to production, and then to different types of final consumption.

- The paper uses demand driven input-output attribution methods to identify hazardous waste hotspots in the supply chains of different final consumption goods and consumption groups. 


\section{Can hazardous waste supply chain 'hotspots' be identified using an input-output framework?}

\section{Introduction}

Input-output accounting and analytical (multiplier) techniques have been shown to be useful tools in assessing a range of issues relating to economic structure and related environmental issues (see Miller and Blair, 2009; and Nakamura and Kondo, 2009). This paper uses inputoutput analysis techniques to better frame the connections between the production of hazardous waste, final consumption of goods driving this production, and the management of these waste streams. For decision makers, including policy makers, the techniques explained in this paper, and illustrated through a UK regional case study, improve the understanding of the demand and supply pathways and linkages underlying hazardous waste production. We show how the integration of data on regional economic structure and hazardous waste generation permits a detailed exploration of the regional hazardous waste economy as it relates to local production. The approach provides valuable information for decision makers in developing waste strategies and policy support as it relates to hazardous waste minimization. The paper also shows how demand-driven input-output attribution methods can be used to identify hazardous waste hotspots in the supply chains of different final consumption goods and consumption groups, again yielding valuable information for decision makers.

The paper is structured as follows. Section 2 provides background on the need to understand the drivers of hazardous waste flows, the connections between consumption and hazardous waste management options, and provides an outline of the policy and regulatory framework. Section 3 describes the methodology and Section 4 discusses the results from our hazardous waste economy case analysis, showing the types of information that lever value for decision makers. Section 5 discusses the further implications of these results and concludes by providing directions for future research.

\section{Background}

Hazardous wastes are those wastes that are considered harmful or potentially harmful to human health and/or the environment. ${ }^{1}$ Figure 1 outlines the connections between final

\footnotetext{
${ }^{1}$ The Environment Agency defines hazardous wastes as those that are either immediately harmful to human health or the environment or potentially harmful in the future. More specifically, wastes are classified as hazardous by the Environment Agency if they have one or more of the following properties: explosive, oxidizing, highly flammable, flammable, irritant, harmful, toxic, carcinogenic, corrosive, infectious, toxic for reproduction, mutagenic, sensitizing, ecotoxic, or wastes which release toxic or very toxic gases in contact with water, air, or acid.
} 
consumption groups in an economy (such as households and government consumption), and the production and then management of hazardous waste. Thin arrows indicate the direction of economic flows while thick arrows show the flow of hazardous waste by products. Importantly here it is necessary to understand that we consider the problem from the perspective that the decisions of final consumers of products drive activity in the economy thereby creating (derived) demand for hazardous wastes up the supply chain, and indeed, create hazardous waste perhaps far from the domestic economy through hazardous waste embodied in trade (for a discussion of these trade issues see Jensen et al., 2011). Figure 1 shows that economic activity and associated hazardous waste production flows from different public and private final consumption demands (in different geographical regions) for goods and services produced in the domestic economy. These in turn rely on primary and intermediate inputs, with the latter relying on both internal and external supply chains. The hazardous waste flows driven by the chain of economic activity are then subject to a series of management options which can include incineration, landfill, recycling and reuse, and more complex treatments that may take place within or without the domestic economy (see Table 1 for a summary of management options). This scale of hazardous waste production is significant. For example, the Environment Agency (2010) revealed that hazardous waste sent for disposal and recovery in England and Wales in 2008 totaled about 6.6 million tonnes.

\section{Table 1 and Figure 1 about here}

This process of hazardous waste production, trade and treatment is subject to an intensifying regulatory regime and this deepening of regulatory requirements also underlines requirements for better information on the determinants of hazardous waste production and links to different types of consumption activities. For example, the UK is bound by EU legislation including the 1991 Council Directive on Hazardous Waste. This defined hazardous waste and a series of management and traceability objectives, and ultimately became part of the EU Waste Framework Directive (WFD - see EU, 2008). The WFD (EU, 2008) set out a waste hierarchy in terms of waste prevention and management legislation and policy i.e. in priority order: prevention; preparing for re-use; recycling; other recovery (e.g. energy recovery) and finally disposal. The WFD challenges EU member states to encourage the options that deliver the best overall environmental outcome. Guidance notes on applying the waste hierarchy to hazardous waste were published by the UK government (DEFRA, 2011; see also DEFRA, 2010).

Hazardous wastes do not include radioactive wastes, decommissioned explosives, waste waters, or animal by-products (except those destined for incineration, landfilling, or use in a biogas or composting plant). 
In effectively planning and developing hazardous waste strategy and changing consumption behaviors a better understanding of the process of hazardous waste generation and linking management options to types of final consumption is important. For example, it is domestic households, one component of final consumption, who in particular have much to lose in terms of bearing environmental externalities (for example, the presence of landfill sites) such that there can be value in communicating to consumers how their consumption decisions link to both amounts of hazardous waste and management options. The need for this type of information is particularly important where selected (often cheaper) hazardous waste management options result in a reduction in human welfare directly, but also have more subtle welfare effects linked to environmental degradation. Moreover, Figure 1 shows that government consuming on behalf of households is also identifiable as a final consumption group, so that changes in the pattern of consumption of those that develop policy may be considered.

The type of concerns and information requirements outlined above provide a link between the research in this paper, and operations research that explores the transportation of hazardous waste, flow routing, and the location of treatment facilities and specialised landfills (see for example, Giannikos, 1998; Zhang et al. 2000; and Samalioghu, 2013). A further related issue is trade in hazardous waste itself and how far industry production that creates hazardous waste is conterminous with where goods are consumed and where waste arising is managed, and with links here to the pollution haven hypothesis in response to regulatory variation (see for example Cave and Blomquist, 2008; Baggs, 2009; Fikru, 2012; and Kellenberg, 2012).

In summary there is a requirement to understand the process through which hazardous waste production and management connects to final consumption groups and consumption decisions. Through the application of techniques to attribute hazardous waste flows through the supply chain it is more likely that an efficient balance can be struck between policy that changes emphasis on stimulating different types of final demand and 'nudging' patterns of consumption therein, and policy that regulates industries directly. Furthermore the application of input-output techniques allows a better understanding of the interplay between the production of hazardous waste, the benefits from the consumption of industry goods that have directly and/or indirectly resulted in hazardous waste production, policy jurisdiction, and the location of management options (i.e. who bears the full economic costs associated with treatment options). 


\section{Method and Data: Hazardous waste flows attribution}

\subsection{Input-output analysis and waste}

Input-output tables reveal the different industries that make up an economy, and then how they 'fit' together in terms of their sales and purchasing patterns. Each industry also uses a combination of primary or non-produced inputs (labour and capital/land) and intermediate or produced inputs, some of which are imported so that each industry relies to a greater or lesser extent on local, regional, national and then international markets. The tables allow comparisons between industries in terms of their pattern of resource use, and the sectoral and geographical destinations of their outputs, including the level of interregional and international export activity (see for example, Miller and Blair, 2009).

The method used in this paper is developed around input-output tables, using techniques that have a wide application in informing environmental management and better understanding the connection between different types of production and consumption activities, and associated environmental effects (see for example, most recently Miller and Blair, 2009; Dietzenbacher and Velazquez, 2007, McGregor et al., 2008). Here we focus on the informational content and analytical facility offered by single region input-output tables. Thus, at this stage we focus on hazardous waste embedded in domestic supply chains but with consideration of the waste embedded in total regional exports (we also make note of the other side of the relationship only in terms of hazardous waste generated in Wales treated elsewhere in the UK). Consideration of the full set of flows in Figure 1 would require estimation and use of a full national interregional and/or global international input-output framework, which is an objective for future research.

Input-output tables have been specifically developed to consider waste management issues. For example, Nakamura (1999) and Nakamura and Kondo (2002), developed a waste inputoutput model that integrates waste creation and management options, while Nakamura and Kondo (2009) review the extended use of waste input-output models, for example in terms of analysis of sustainable consumption, life cycle analysis and materials flows analysis. Jensen et al. (2013) examine general waste attribution in a regional economic setting, taking a preliminary step towards the hotspot analyses presented here, but with no account of alternative management options (for allied waste analysis in an input-output framework, see also Choi et al., 2011; Xu and Zhang, 2009). 
Importantly the input-output framework, incorporating waste analysis, permits reconciliation between what are, normally, just a few key hazardous waste producing industries but extends to explain the demand drivers of this production. These demand drivers can be separated into the intermediate demands placed (directly and/or indirectly) by other industries on these key firms' outputs and different types of final consumer demand. Crucially in the demand-driven input-output framework, intermediate demands are determined endogenously, with all production activity in the system ultimately driven by exogenously determined final consumption demands. This paper applies the conventional demand-driven input-output attribution method with detailed decomposition of results to identify hazardous waste hotspots in the supply chains of different final consumption goods and consumers. In this way the framework is particularly valuable because it provides information for policymakers who may be seeking a balance between policies to regulate sectors and policies to modify or 'nudge' selected consumption behaviours (for example, including education programmes).

\subsection{Methodology}

The inter-industry matrix of an input-output table has $\mathrm{N}$ rows and columns, reporting the composition of output and input respectively for $\mathrm{i}=\mathrm{j}=1, \ldots, \mathrm{N}$ sectors and all units are expressed in terms of value (£m). Reading along each row, $x_{i}$ is the output of sector $i$, which is the sum of intermediate demands from each production sector $\mathrm{j}$, and final consumption demand, $\mathrm{y}_{\mathrm{i}}$, for the output of sector $i$. Final consumption demand is then composed of $z=1, \ldots, Z$ different types of final consumers (i.e. including domestic households, government etc.)

From the input-output tables, we generate the basic conventional demand-driven environmental input-output system as derived by Miller and Blair (2009) which takes the following form:

$$
\mathbf{W}=\mathbf{\Omega}^{\mathbf{P}}[\mathbf{I}-\mathbf{A}]^{-1} \mathbf{Y}
$$

(Where bold font upper case denotes matrices; bold font lower case denotes vectors, while nonbold lower case implies a scalar.) $\mathbf{Y}$ is the NxZ matrix of exogenous final consumption expenditures while $[\mathbf{I}-\mathbf{A}]^{-1}$ is the NxN multiplier matrix, commonly referred to as the Leontief inverse, or Type I multiplier matrix (Miller and Blair, 2009). The Leontief inverse, which we also refer to as matrix $\mathrm{L}$ below, has elements $\mathrm{b}_{\mathrm{ij}}$, representing the output in each industry $\mathrm{i}$ that 
is required to meet final demand for commodity output $\mathrm{j}$. Hazardous waste is introduced to the system using the basic Leontief environmental input-output extension (Leontief, 1970; also see Miller and Blair, 2009; Nakamura and Kondo, 2009). This involves defining a KxN matrix, $\mathbf{\Omega}^{\mathbf{P}}$, with elements $\omega_{\mathrm{ki}}=\mathrm{w}_{\mathrm{ki}} / \mathrm{x}_{\mathrm{i}}$, where $\mathrm{w}_{\mathrm{ki}}$ is the total physical amount (tonnes) of each type of hazardous waste (defined by the fate, or management method, of that waste - see e.g. Table 1) $\mathrm{k}$ generated by each production sector $\mathrm{i}$ in producing its output, $\mathrm{x}_{\mathrm{i}}{ }^{2}$

Thus, the matrix $\Omega^{\mathbf{P}}[\mathbf{I}-\mathbf{A}]^{-1}$ is a $\mathrm{KxN}$ matrix of output-waste multipliers with elements $\omega \mathrm{L}_{\mathrm{kj}}$ representing the total amount in tonnes of each type of hazardous waste generated in production (across all $\mathrm{N}$ production sectors) to meet one monetary unit (£million) of final demand for sectoral output $\mathrm{j}$.

Given our interest in developing material for decision makers, we consider hazardous waste hotspots (defined by different treatment options) in the supply chain serving any one kind of final demand, $\mathrm{z}$, for any industry/commodity output $\mathrm{j}$. That is we examine the contribution of individual supply chain elements that combine to give the overall multiplier effects from [1]. This is done by decomposing the calculation of matrix $\mathbf{W}$ for each hazardous waste management, $\mathrm{k}$, and each type of final consumer, $\mathrm{z}$. The process involves first multiplying the rows of the NxN Leontief inverse $[\mathbf{I}-\mathbf{A}]^{-1}, \mathbf{L}$, by the corresponding $\omega_{\mathrm{ki}}$ coefficient for the industry producing the output represented in that row. This is done for each hazardous waste management type $\mathrm{k}$ in turn so that the result is a set of hazardous waste-output multiplier matrices that we will label $\omega_{\mathbf{L}^{\mathbf{k}}}$. For each hazardous waste management type $\mathrm{k}$, the matrix $\omega \mathbf{L}^{\mathbf{k}}$ is stated as follows:

$$
\left[\begin{array}{cccc}
\mathrm{w}_{\mathrm{k} 1} \mathrm{~b}_{11} & \mathrm{w}_{\mathrm{k} 1} \mathrm{~b}_{12} & \ldots & \mathrm{w}_{\mathrm{k} 1} \mathrm{~b}_{1 \mathrm{n}} \\
\mathrm{w}_{\mathrm{k} 2} \mathrm{~b}_{21} & \mathrm{w}_{\mathrm{k} 2} \mathrm{~b}_{22} & \ldots & \mathrm{w}_{\mathrm{k} 2} \mathrm{~b}_{2 \mathrm{n}} \\
\vdots & \vdots & & \ddots \\
\mathrm{w}_{\mathrm{kn}} \mathrm{b}_{\mathrm{n} 1} & \mathrm{w}_{\mathrm{kn}} \mathrm{b}_{\mathrm{n} 2} & \cdots & \mathrm{w}_{\mathrm{kn}} \mathrm{b}_{\mathrm{nn}}
\end{array}\right]
$$

The elements $\omega_{\mathrm{ki}} b_{\mathrm{ij}}$ of each of the $\mathrm{K}$ variants of [1] can then be examined to find the largest output-hazardous waste impacts per (monetary) unit of final consumption demand in the industry/commodity output supply chain serving sector $\mathrm{j}$. If we then multiply down the columns of the extended matrix for each hazardous waste type $\mathrm{k}$ by a particular element of

\footnotetext{
${ }^{2}$ This study abstracts from any production of hazardous waste by final consumers.
} 
final demand, $\mathrm{yjz}_{\mathrm{j}}$, for the industry/commodity output whose domestic supply chain is represented by that column, we can compute the full direct and indirect hazardous waste generation directly or indirectly embodied in each intra- and inter-sectoral transaction. This allows us to identify the magnitude of any one hotspot of interest (i.e. adding the scale of the final demand expenditure in question to the consideration of direct plus indirect waste intensity in [2]). For each type of final demand, z, we label each of the matrices $\boldsymbol{\omega} \mathbf{L} \mathbf{Y}^{\mathbf{k z}}$. This means we have $\mathrm{K}$ times $\mathrm{Z}$ matrices, each of which takes the following form:

$$
\left[\begin{array}{cccc}
w_{k 1} b_{11} y_{1 z} & w_{k 1} b_{12} y_{2 z} & \cdots & w_{k 1} b_{1 n} y_{n z} \\
w_{k 2} b_{21} y_{1 z} & w_{k 2} b_{22} y_{2 z} & \cdots & w_{k 2} b_{2 n} y_{n z} \\
\vdots & \vdots & & \ddots \\
w_{k n} b_{n 1} y_{1 z} & w_{k n} b_{n 2} y_{2 z} & \cdots & w_{n} b_{n n} y_{n z}
\end{array}\right]
$$

Thus, each element $\omega_{\mathrm{ki}} \mathrm{b}_{\mathrm{ij}} \mathrm{y}_{\mathrm{jz}}$ of each of the K,Z variants of [3] tells us how much hazardous waste destined for management type $\mathrm{k}$ is produced in each sector $\mathrm{i}$ as a result of total final demand expenditure on commodity output $\mathrm{j}$ by consumer $\mathrm{z}$. We can also focus on just $\mathrm{K}$ matrices where total final demand for each commodity output, $y_{j}$, is used in place of $y_{j z}$ in the calculation of [3]. Examination of the elements of each matrix thereby permits identification of the absolute magnitude of hazardous waste generation hotspots in the domestic supply chains of different types of final consumption demand for different domestic commodity outputs. Here this is done for the accounting period to which the input-output data relate but the conventional input-output model is also commonly used to consider the impact of marginal changes in final demand. ${ }^{3}$ In the results in Section 4, we are able to use equation [3] to identify the elements of each sector i's direct hazardous waste generation that is attributable to its own and other sector final demands by reading along the row for any one sector $\mathrm{i}$. By subtracting the latter component and adding the corresponding sector $\mathrm{j}$ column information for that sector as an intermediate purchaser (i.e. waste generated in other sectors to support final demand for sector $\mathrm{j}$ output), we are able to move between consideration of waste that is directly generated by a sector and what is (directly and indirectly) attributable to final demand for its output. Moreover, working with both [2] and [3] it is also possible to consider whether a hotspot is determined by the hazardous waste intensity of the production point and/or the scale of the final demand flow in question. All the analysis is broken down in

\footnotetext{
${ }^{3}$ Though such use of the input-output model is subject to additional assumptions regarding supply conditions and technology (see Miller and Blair, 2009, and Section 5 below).
} 
terms of the type of treatment/disposal of the hazardous waste, allowing us to more fully consider the implications of each hazardous waste hotspot.

\subsection{Regional economic and hazardous waste data}

By way of an example we use the case of the Welsh economy where input-output tables were available for 2007 , together with detailed hazardous waste data that could be matched to specified industries. The Welsh input-output tables detail the purchases and sales of 73 industries (see Appendix) and financial flows between industry, with a sectoral level account (matrix $\mathbf{Y}$ ) reporting seven different types of final demand (households, government, addition to stocks, capital formation, tourists, and exports to the rest of the UK, and then exports overseas - see Bryan et al., 2004 for further details of the general Welsh input-output framework).

Summary data for direct hazardous waste generation by industry in the UK were collected from the 2007 Hazardous Waste Interrogator, a database of hazardous waste generation in the UK that is published annually by the Environment Agency. There are 8 management options considered in our analysis (see earlier Table 1).

The hazardous waste data are used in conjunction with the industry sales and purchases information derived from the input-output tables to calculate equation systems [1] to [3] above and produce the results analysed in the next section.

\section{Results of hazardous waste stream attribution analysis}

This section presents the results of the input-output based hazardous waste tracking system detailed in Section 3 when applied to the case study of Wales in the accounting year of 2007. The section begins by describing the amounts of hazardous waste being produced in Wales in terms of industry and management options, using information from the Environment Agency Hazardous Waste Interrogator. The discussion of attribution is arranged in terms of two hazardous waste management options of particular policy concern within the waste management hierarchy. These are treatment and landfill. Under each of these management options, we focus on industry examples that are important in terms of (a) the magnitude of direct generation of the hazardous waste streams to particular management options resulting from production and/or in terms of (b) indirect supply chain reliance on production that is 
accompanied by hazardous waste generation. Following from this the section moves to consider why the information presented is of importance to decision makers.

\subsection{Hazardous waste produced in Wales}

The Environment Agency Hazardous Waste Interrogator reveals that in 2007, Wales generated over 240,000 $(241,687)$ tonnes of hazardous waste. Much of this (just over 69\%) was directly generated in just 7 of the 73 industries in the Welsh economy: "Sanitary Services" (18.1\%), “Aluminum and Non-Ferrous Metals" (18.1\%), "Construction” (9.9\%), "Health and Social Work" (6.3\%), "Forging/Pressing (6.7\%), "Oil Processing" (6.0\%) and "Iron and Steel" $(4.2 \%)$. Table 2 shows that almost half of this is recycled or reused. Another $23 \%$ is sent for treatment and $16 \%$ is transferred for either disposal or recycling at a later date. The less desirable disposable methods, landfill and incineration, account for $12 \%$ and $2 \%$ respectively. Table 2 also provides a comparison of these percentages with similar percentages for hazardous waste generated in the rest of the U.K.

Note that hazardous waste is not necessarily managed or disposed of in the same location or even region of generation. Overall, more than half of the total hazardous waste generated in Wales is managed or disposed of outside of Wales. For example, in the cases of treatment and transfer for disposal, the Hazardous Waste Interrogator shows a relatively high share (40$50 \%$ ) does take place in Wales. On the other hand, almost all of hazardous waste to landfill (around 99\%) goes to sites outside of Wales. Only 10\% of waste incineration with energy recovery and just over $20 \%$ of incineration without energy recovery take place in Wales. This is a cause for concern given that these are the less desirable waste management methods in the UK Environment Agency's waste hierarchy. In terms of the sectoral sources of direct hazardous waste generation, these vary radically relative to the overall picture discussed above. For example, according to the Hazardous Waste Interrogator, while just less than 10\% of total hazardous waste generation takes place in Construction, $61 \%$ of total waste to landfill is directly generated in this sector. On the other hand, Aluminum and Non-Ferrous Metals, the second biggest direct generator of hazardous waste identified, sends just over $95 \%$ of this to recycling/reuse, which directly accounts for $36 \%$ of hazardous waste to this destination. In the case of the other management option we focus on here, treatment, Oil Processing, Forging and Pressing and Health and Social Work together directly account for just over $50 \%$ of the hazardous waste with this fate. In the next section, we consider the cases of treatment and landfill in more detail, specifically examining the contribution of the input-output approach 
detailed in Section 3 to developing a better understanding of the structure of the hazardous waste problem in the case study region of Wales, taking into account demand-side drivers of activity in the sectors identified above.

\subsection{Hazardous waste for treatment management option}

We begin by considering the industrial composition of the total generation of hazardous waste that is then sent for treatment in Wales, for the accounting year of 2007. Table 2 reports that 54,991 metric tonnes of hazardous waste were directly generated through the production activities of the 73 Welsh industrial sectors identified in the input-output tables (see Appendix) and consequently sent for treatment. This equates to $22.8 \%$ of total hazardous waste generation in Wales in 2007. Just under half of this, 27,463 tonnes, was reported as being treated within Wales, with the rest sent to destinations elsewhere in the UK (hereafter referred to as the rest of the UK, RUK) for treatment.

We first conduct an attribution of the hazardous waste sent to treatment to the seven types of final consumer/end user using equation [1]. The first column of Table 3 reveals that, in terms of consumption that takes place within Wales, the largest shares of hazardous waste going to the treatment option are attributable to household consumption (11\%) and Welsh government consumption (20\%). However, the bulk (64\%) of hazardous waste generation for treatment in Wales in 2007 was attributable to export demand for the goods and services produced across all 73 sectors. This is divided between export demand from the rest of the UK (RUK), 47.4\%, and the rest of the world (ROW), 16.7\%. The Hazardous Waste Interrogator data showed that around $50 \%$ of treated hazardous waste was sent to RUK for that treatment. The above analysis reveals that this is almost entirely balanced by demand from this source (RUK exports) that underlies its generation.

\section{Tables 3 \& 4 about here}

Table 4 provides a more detailed analysis for the treatment option. The results in Column B of Table 4 identify the five largest direct generators/producers of hazardous waste that goes to the treatment management option. The largest share $(21.7 \%$, Column B, Table 4$)$ is generated in production in the Oil Processing sector. Utilising the decomposition system in equation [3], we find that Oil Processing also comes out on top in terms of the share that is attributable to final demand for its own output (Column H, 20.5\%). 
The direct sector intensity (Column B) and Type I attribution results (Column H) relating respectively to the production of and final consumption demands for sectoral outputs are similar because Oil Processing is not strongly linked to other sectors within the Welsh economy. Most of its output goes to final demand, particularly RUK exports (62.2\%), and the sector had high import intensity (only $12.6 \%$ of intermediate inputs are produced in Wales). This is reflected in the relatively low Type I output multiplier of 1.15 reported in Column C. The relatively high direct intensity for hazardous waste to treatment in Oil Processing is reflected through comparison of the figures in Columns A and D: direct effects account for 96.6\% of the Type I hazardous waste (treatment) output multiplier.

However, we should also note that the final consumption pattern (in terms of the type of final consumer) for the output of the Oil Processing sector differs significantly from the overall picture discussed at the start of this section, where $47.4 \%$ of total treated hazardous waste was generated in the production of output to meet RUK export demand (see Table 3). RUK export demands for the sector's output and other sectors with (albeit limited) backward linkages to Oil Processing are much more important, driving $67.9 \%$ of sectoral output and hazardous waste production (Column I, Table 4), with ROW exports driving a further $23.5 \%$.

A more complex picture emerges when we consider other industries that have stronger links within the Welsh economy. An example is the Health and Social Work sector, which ranks third in Table 4 as a direct producer of hazardous waste that is destined for treatment $(8,133$ tonnes- see Column B of Table 4), but second if we consider the problem in terms of final consumption demand driving industrial activity $(8,506$ tonnes or $15.5 \%$ in Column $\mathrm{H}$ of Table 4). The difference between these two results is elucidated through application of the decomposition system in equation [3]. This produces the results reported in Columns E, F and $\mathrm{G}$ of Table 4, which are used to move between consideration of waste that is directly generated in the Health and Social Work sector and waste that is (directly and indirectly) attributable to final demand for its output. Column E shows that 8,015 tonnes are generated within Health and Social Work to support own-sector final demand. Subtracting the 118 tonnes generated to support final demand for the output of other sectors (Column F) from the 8,133 tonne direct generation figure in Column B and adding the 491 tonnes generated in other sectors to support final demand for Health and Social Work (Column G), we have the Type 1 result of 8,506 tonnes in Column H. Further, the Column I entry for Health and Social Work shows that domestic government final consumption dominates in terms of the type of 
end use driving sector activity (93\%, compared to just $5.5 \%$ by households and only $1.5 \%$ in RUK export demand). Indeed, government final consumption dominates the sector's activity levels more generally. Intermediate sales to other Welsh industries are small (only $1 \%$ of output in the underlying input-output tables).

Moreover, the direct hazardous waste (treatment) intensity of Health and Social Work is lower (0.996 tonnes per £1million output in Column A) than that in the Oil Processing and Forging and Pressing sectors that rank higher on direct generation in Table 4. In consequence, the Health and Social Work figure in Column F is relatively small. Its Type I output multiplier (Column C) is higher (1.54) than those of the other top ranking sectors and direct hazardous waste (treatment) effects account for a lower share $(68.4 \%)$ of the total direct plus indirect effects captured in the Type I hazardous waste (treatment) output multiplier in Column C. This is reflected in the fact that $89 \%$ of Health and Social Work's output multiplier and 94\% of its hazardous waste to treatment multipliers (Equation [2]) are ownsector effects. The input-output table reveals that $75 \%$ of Health and Social Work's domestic intermediate purchases are own-sector: the larger shares reflected in the multipliers are due to indirect own-sector purchases (i.e. other industries purchasing from Health and Social Work in supplying to it) and the relatively high direct hazardous waste to treatment intensity of the sector. This also means that the key hotspot impact in the Health and Social Work supply chain is located within the industry itself and that this is largely attributable to Welsh government demand.

In the case of the second ranked direct producer of hazardous waste destined for treatment, on the other hand, stronger forward linkages mean that Forging and Pressing is key hot spot in the supply chain of a number of Welsh industries that are themselves not large direct generators. For example, just over $42 \%$ of the 2,867 tonnes reported in Column F for Forging and Pressing is hazardous waste generated in that sector to support final demand for (motor and other) vehicle manufacture in Wales, where $68 \%$ of output is exported to RUK. This is a hotspot accounting for $29 \%$ of the hazardous waste to treatment embedded in the domestic supply chain of Welsh vehicle manufacture (combined impact in Sectors 38 and 39 in the Appendix). The domestic Forging and Pressing sector is an important hazardous waste to treatment hotspot in the supply chains of numerous sectors in the Welsh economy, with various orders of magnitude but with Column I of Table 4 showing that export demand from RUK is the main underlying driving force. 


\subsection{Hazardous waste to landfill management option}

Table 3 shows that a smaller amount, 29,487.9 metric tonnes of hazardous waste, was generated through the production activities of the 73 Welsh industrial sectors identified in the inputoutput tables and consequently sent to landfill. Total hazardous waste to landfill equates to $12.2 \%$ of total hazardous waste generation in Wales in 2007. However, a much smaller share (only $1.3 \%$ or 369 tonnes) of this was treated within Wales, with the rest sent to landfill destinations elsewhere in the UK.

When we conduct the Type I attribution (see Table 3, final column) to the seven types of final consumer/end user using equation [1], we find a significantly different profile to the treatment option case, with $13.6 \%$ attributable to Welsh household consumption and $9.7 \%$ to Welsh government consumption, but a larger share $(33.7 \%)$ to Welsh gross domestic fixed capital formation. Again, export demands are important, with $34.3 \%$ attributable to RUK export demand for the goods and services produced across all 73 sectors, and a further $7.7 \%$ to ROW export demand. However, there is a marked shift relative to the treatment option in terms of the lower importance of Welsh government and export demands and greater importance of Welsh capital formation in driving hazardous waste generation going to the landfill management option. Moreover, the input-output attribution analysis reveals that inter-sectoral effects are more important in considering the landfill case.

\section{Insert Table 5 about here}

Table 5 provides a more detailed analysis for selected industries and shows why capital formation is relatively important here as the ultimate final demand determinant of hazardous waste creation. Table 5 reveals the dominance of the Construction industry both in terms of direct hazardous waste generation (Column B) and (to a lesser but still hugely significant extent) that attributable to final consumption demand for the sector's output (Column H). The result in Column B of Table 5 shows that $61.1 \%$ (18,009 tonnes) of hazardous waste generated in Wales in 2007 that ultimately went to landfill was generated in the Construction sector. In contrast to the case of Oil Processing as the top-ranking direct producer, but more in common with the second-ranking Forging and Pressing in Table 4, note from the result in Column F of Table 5 that hazardous waste flows associated with Construction's intermediate sales are important in determining the larger shift between the direct accounting perspective (Column B) and the Type I attribution to final consumption for sectoral output (Column $\mathrm{H}$ ). Examination of the underlying input-output tables reveal that Construction sold $34 \%$ of its 
output to other Welsh production sectors in 2007 and this equates to a reduction of 4,018 tonnes in making this shift. While Construction has relatively strong backward linkages (the Type I output multiplier in Column $\mathrm{C}$ is 1.466 ), its direct waste intensity (3.532 tonnes per $£ 1$ million output in Column A) dominates (direct effects account for $83.4 \%$ of the Type I hazardous waste to landfill multiplier of 4.237 tonnes in Column D) so that a much smaller amount (179 tonnes in Column G) is added to account for indirect effects in the Welsh supply chain. Thus, the Type I attribution result in Column I (14,170 tonnes, equating to $48.1 \%$ of total hazardous waste to landfill) is significantly smaller than the direct result in Column B. However, this is still a dominating share.

In terms of the hotspot analysis of the composition of the Type I attribution result (Column H) for Construction, $98 \%$ is located in the Construction sector itself. However, direct generation of hazardous waste to landfill in Construction is an important hotspot in the regional supply chains of many other industries. For example, in Table 5 we report results for Real Estate etc. and Public Administration. In the case of the Real Estate etc. sector, $96.2 \%$ of the 0.211 tonnes per $£ 1$ million final demand multiplier result in Table 5 Column D is found in the Construction sector (equation [2]). This reflects the direct hazardous waste to landfill intensity of Construction: only $48 \%$ of the Real Estate sector's domestic intermediate purchases are from the Construction sector but almost all of the Real Estate landfill multiplier is traced back to Construction. The key supply chain hotspot in terms of different sources of final demand for Real Estate sector is the indirect supply chain impact in Construction from direct household demand for Real Estate service output. Direct final demand expenditure by households on Real Estate services is $£ 5239.6$ million, which, multiplied by the $96.2 \%$ share of the Type 1 hazardous waste multiplier that is located in the Construction sector $(0.203)$ equates to a hotspot of 1,063 tonnes. This translates to the result in Column I where households drive $78.4 \%$ of the Type I attribution to final demand for Real Estate output.

In the case of Public Administration, reading along the row in Table 5, the key result is that the amount of total hazardous waste to landfill that was generated in 2007 and can be attributed to Public Administration grows from just 46 tonnes $(0.2 \%$ of the total) under the direct analysis (Column B) to 1,218 tonnes (4.3\%) of the total under the Type I attribution to final demand for industry output (Column H). While Welsh Government dominates as the final demand driver (supporting 93.8\% of output and hazardous waste attributable to Public Administration output in column I), the profile is quite different to other public services such 
as the Health and Social Work case considered above for the Treatment option, or Sanitary Services (which also appears in both Tables 4 and 5 with own-sector impacts dominating). In contrast, the results of using the equation systems [2] and [3] to examine the case of Public Administration reveals that only $3.6 \%$ of the hazardous waste to landfill embodied in the Public Administration supply chain is located in own-sector effects (Column B result divided by Column $\mathrm{H}$ result in Table 5). Here, Construction provides the most important hotspot impact in the supply chain supporting final demand for Public Administration output, accounting for $76 \%$ of the 1,263 tonnes in Column $\mathrm{H}$. The second most important hotspot in the Public Administration sector is hazardous waste to landfill generation in Sanitary Services, at $10.9 \%$ or 137 tonnes. $^{4}$ A third, small but still noteworthy (at $3.4 \%$ of the 1,263 total in Column H), hotspot in the Public Administration supply chain is located in the second highest ranking sector in terms of its direct generation, which is Wood Products (second row of Table 5). Thus, the implication is that any public sector supply chain management aimed at limiting hazardous waste generation will be more complex in the case of Public Administration than in Health and Social Work or Sanitary Services.

\subsection{Information for decision makers}

We now reflect on how the information in the preceding analysis can be used by decision makers, starting with the information in Table 3. This showed which final consumption categories drive the production of hazardous waste that goes to the treatment and landfill options. For decision makers this information is useful because it hints at where policy resources might be placed to make final consumption 'responsibility' groups aware that it is their choices that drive the production of wastes that go to management options that are associated with a potentially higher level of externalities. The attribution of hazardous waste to final consumption groups also reveals how far regional policy makers might have the leverage to control consumption behaviours. For example, Table 3 shows that with the treatment option, nearly two thirds of final consumption relates to exports (RUK and overseas) such that there is likely to be less scope to influence consumption choices here. However, where there is stronger attribution to regional households and regional government, then there may be greater scope to enact policy or guidance, or to educate on the importance of applying the waste hierarchy. In the case of landfill there was a lower attribution to exports

\footnotetext{
${ }^{4}$ While we have not examined the Sanitary Services results under the treatment option in detail in the text, it is worth noting that an even larger hotspot relationship exists between the two sectors there (with 218 tonnes or $23.4 \%$ of the total hazardous waste to treatment attributable to final demand for Public Administration output being generated in the Sanitary Services sector).
} 
but higher attribution to domestic households and domestic capital formation over which regional authorities will have more control through regulation and education.

Recall Tables 4 and 5 provide in-depth information on individual industries. There are several ways in which this could specifically inform decisions. First, the information in Column A relates to direct hazardous waste generation to the treatment/landfill management options per $£ m$ of output. This shows decision makers the relatively more waste intensive sectors with respect to this selected management option. However, this information can, when combined with forecasts of structural change in the regional economy, identify the expected change in hazardous waste output. This can inform choices on where policy resources might be focused for education and regulatory purposes. Resulting forecasts of hazardous waste outputs could also inform choices about future infrastructure needs in dealing with hazardous waste. Column A in combination with Column B data relating to waste directly generated in Wales, also provides a useful benchmark for accounting the current hazardous waste economy.

The information in Column D of Tables 4 and 5 can be used to show how a unit shock to final demand for the output of industries is likely to create hazardous waste directly and indirectly in the regional economy. For policymakers this type of information identifies the root causes of production of hazardous waste going to the different management options. This is particularly useful when combined with information in Column I which shows the elements of final consumption that cause the waste flow. For individual industries, Column D information allows policymakers to examine where education and regulatory resources might be focused. For example, in the preceding analysis relating to the treatment management option the Oil Processing sector produced largely for export such that policymakers in the region have less jurisdiction and leverage over this element of final demand. Arguably here the consumption driver of this hotspot is outside the immediate jurisdiction of the regional government. In this case policy resources might be focused more on the industry itself which is an important direct producer of hazardous waste and with little hazardous waste embodied in its regional supply chain. However in the case (Table 4) of Health and Social Work, conclusions for policy makers might be different as the main final demand driver is Welsh Government consumption. This implies that more leverage in reducing waste might be achieved by understanding the process through which government demands feed through to hazardous waste output in this sector. The analysis shows that there is more scope in the Health and Social Work industry for a mix of consumption- and production-focused 
approaches that educate in terms of changing final consumption behaviours, but also deal with the hotspot, which is in the Welsh Health and Social Work industry itself.

The attribution to final demand groups in Column I of Table 4 and 5, and in Table 3, also reveals to policy makers in Welsh Government how far it is local consumption choices, rather than external demands, that drive hazardous waste production (and the type of management options in question). There is increasing interest in many regions/nations in estimating consumption footprints in terms of externalities/resources like carbon, general waste and water. The accounting introduced in Tables 3 to 5 is an important step in developing a consumption-based accounting and mitigation approach for hazardous waste, and with the analysis of selected industries in Tables 4 and 5 revealing the proportion of hazardous waste produced locally that is necessary to meet regional final demands as opposed to export (external) demands. In doing so, the analysis highlights how there is likely to be a need for a combination of consumption- and production-focussed accounting and responses. Generally, it provides a foundation for policy and economic analyses that relate local economic benefits from the export production (in terms of employment and gross value added in the waste producing industries) to local costs in terms of hazardous waste production and management.

The information in Tables 4 and 5 Columns E, F and $\mathrm{G}$ allows decision makers to consider, in the case of individual industries, how far hazardous waste production in the industry is a result of meeting final demands for its own products and/or how far it is producing hazardous waste that is embodied in trade with other regional industries. The case analysis in Tables 4 and 5 shows that in general in the big hitting hazardous waste producers (in terms of waste going to treatment and landfill management options) that hazardous waste production is generated to meet final demands for the industries own products. However in some sectors, for example, Forging and Pressing (in Table 4) and Sanitary Services (Tables 4 and 5) and Construction (Table 5), that a significant proportion of their own hazardous waste production was embodied in their trade to other sectors in the regional economy. For selected industries such as these, it is important for decision makers to focus some resources on sectors to whom the 'own' sector sells to revealing to these sectors the connection between their purchasing behaviour and hazardous waste production upstream. Again, a more general lesson is that consumption- and production-focussed analyses of waste (and other pollutants/ resource uses) embedded in supply chains are more complex than identifying and considering just one source producer and final consumer. This emphasises the need for a mixed approach. 
In summary the information provided in Tables 3-5 permits decision makers a better view of the process of hazardous waste attribution which might be considered in advance of making choices on regulation, education and new infrastructure development.

\section{Conclusions}

The paper started with the challenge of better understanding the processes and drivers underlying hazardous waste production in an economy, set in the context of tighter regulation and mounting concerns on the externalities associated with selected management options. The paper shows that there is decision making value in more accurately examining how the different components of final demand for the commodity outputs of different sectors impact the supply of hazardous waste and then the requirements for different management options.

The developed approach enabled us to connect hazardous waste production in one industry and the indirect demands driving hazardous waste production elsewhere. This transaction tracking approach is vital in connecting how activity in one industry (and its consumption profile) impacts on another industry's production of waste, and resulting management options. In consequence, the approach adopted allows the speculation of how structural change in an economy might affect overall volumes of hazardous waste production, and forecasting requirements for different management options, by taking due account of both direct and indirect waste production levered by economic changes.

The demand-driven input-output attribution method used here identifies hazardous waste hotspots in the supply chains of different final consumption goods. The results in section 4 of the paper allow detailed decomposition analyses of how hazardous waste in one industry meets the final demands for goods and services from its own sector, but also how far hazardous waste production in one industry serves other sectors' final demands. This allows analysis of how far one sector's hazardous waste production is embodied in intermediate sales to other regional industries. The corollary is the identification of hazardous waste hotspots in the supply chains of different final consumption groups including households, government, capital formation, tourism or exports.

The approach also provides information on the hazardous waste embodied in regional exports (another final consumption group). This allows the identification of how the production of 
externalities by industries in one area is associated with consumption choices in other places. In the location of management options such as hazardous waste landfill and/or incineration there can be community concerns that it is local people who incur the costs for consumption decisions made elsewhere. The review in Section 2 of the paper shows that there has been a great deal of interest in the operations management field in the routing of hazardous waste flows and location of management options such as landfill and incineration. In considering future management options there might be advantages in better communicating where the economic benefits (in terms of wages, salaries and profits) of industrial production that creates hazardous waste occur and then where the full economic costs of managing the externalities occur, in our case within or outside the regional economy. The present method provides some information that may contribute to such a cost-benefit type analysis.

A limitation of the analysis is its restricted breakdown of the trade in hazardous waste intensive goods and services. For example, while the analysis presented in section four of the paper provides better intelligence on the hazardous waste content of exports out of Wales, there is rather less information available on the hazardous waste embodied in regional imports, such that it is not possible to comment on a hazardous waste 'balance of trade'.

To conclude, in developing this work further, it would be useful to explore possibilities and methods to overcome some of the general limitations of the input-output framework in respect of fixed technical coefficients and prices (see Miller and Blair, 2009). In particular to enable an assessment of the implications of changes in the costs of management options, or, for example, were there to be a step change increase in hazardous waste production, how the supply side of the local economy may change to accommodate this. This would involve the development of a computable general equilibrium (CGE) approach where the sectoral information content of input-output would be retained while building in more flexibility and economy dynamism (see Partridge and Rickman, 2010, for a review of regional CGE modeling approaches and issues). ${ }^{5}$

This research could also be extended to other regions of the UK, in the first instance for comparative analysis of results. As hinted earlier in this section, building in information from

\footnotetext{
${ }^{5}$ In Turner et al. (2012) we attempt an integrated input-output accounting and CGE analysis for the case of carbon generation in Wales.
} 
other regions allows the possibility of connecting Welsh industry purchases of imported goods with hazardous waste production elsewhere in the UK, and vice versa.

\section{References}

Baggs, J. (2009). International trade in hazardous waste. Review of International Economics 17, 1-16.

Bryan, J., Jones, C., Munday, M. \& Roberts, A. (2004). Input-output tables for Wales 2000. Cardiff, Cardiff Business School.

Cave, L. \& Blomquist, G. (2008). Environmental policy in the European Union: Fostering the development of pollution havens? Ecological Economics, 65, 253-261.

Choi, T., Jackson, R., Leigh, N. \& Jensen C. (2011) A baseline input-output model with environmental accounts (IOEA) applied to e-waste recycling. International Regional Science Review, 34, 3-33.

DEFRA (2010). A Strategy for Hazardous Waste Management in England. See http://archive.defra.gov.uk/environment/waste/topics/hazwaste/documents/policy.pdf last accessed on October 9th 2013.

DEFRA (2011). Guidance on applying the waste hierarchy to hazardous waste. See https://www.gov.uk/government/uploads/system/uploads/attachment_data/file/69457/pb1368 7-hazardous-waste-hierarchy-111202.pdf last accessed on October 9th 2013.

Dietzenbacher, E. \& Velazquez, E. (2007). Analysing Andalusian Virtual Water Trade in an Input-Output Framework. Regional Studies, 4, 185-196.

Environment Agency (2010). Our corporate strategy 2010 - 2015-Evidence: Waste. See http://www.environment-agency.gov.uk/static/documents/Research/Waste_Final.pdf, last accessed on October $9^{\text {th }} 2013$.

EU Waste Framework Directive (2008). See http://ec.europa.eu/environment/waste/framework/ last accessed on October 9th 2013 
Fikru, M. (2012).Trans-boundary movement of hazardous waste: Evidence from a new micro data in the European Union. Review of European Studies, 4, 3-14.

Giannikos, I. (1998). A multiobjective programming model for locating treatment sites and routing hazardous wastes. European Journal of Operational Research, 104, 333-342.

Jensen, C., McIntyre ,S., Munday, M. \& Turner. K. (2013). Who creates waste? Different perspectives on waste attribution in a regional economy. Regional Studies, 47, 913-933.

Jensen, C., McIntyre, S., Munday, M. \& Turner, K. (2011). Incorporating jurisdiction issues into regional carbon accounts under production and consumption accounting principles. Environment and Planning A, 24, 722-741.

Kellenberg, D. (2012). Trading wastes. Journal of Environmental Economics and Management, 64, 68-87.

Leontief, W. (1970). Environmental repercussions and the economic structure: an inputoutput approach. Review of Economic Statistics, 52: 262-277.

McGregor, P., Swales, J.K. \& Turner, K. (2008). The CO2 trade balance between Scotland and the rest of the UK: performing a multi-regional environmental input-output analysis with limited data. Ecological Economics, 66, 662-673.

Miller, R. \& Blair, P. (2009). Input-Output Analysis: Foundations and Extensions, Cambridge University Press, Cambridge.

Nakamura, S. (1999). Input-output analysis of waste cycles. In: First International Symposium on Environmentally Conscious Design and Inverse Manufacturing, Proceedings, 475-480 (Los Alamitos: IEEE Computer Society).

Nakamura, S. \& Kondo, Y. (2009). Waste Input-Output Analysis. Springer Science, The Netherlands. 
Nakamura, S. \& Kondo, Y. (2002). Input-output analysis of waste management. Journal of Industrial Ecology, 6, 39-63.

Partridge, M., \& Rickman, D. (2010). Computable general equilibrium (CGE) modeling for regional economic development analysis. Regional Studies, 44(10), 1311-1328.

Samanlioglu, F. (2013). A multi-objective mathematical model for the industrial hazardous waste location-routing problem. European Journal of Operational Research, 226, 332-340.

Turner, K., Munday, M., McGregor, P. \& Swales, K. (2012). How responsible is a region for its carbon emissions? An empirical general equilibrium analysis. Ecological Economics, 76, 70-78.

Xu, Y. \& Zhang, T. (2009). A new approach to modeling waste in physical input-output analysis. Ecological Economics, 68, 2475-2478.

Zhang, J., Hodgson, J. \& Erkut, E. (2000). Using GIS to assess the risks of hazardous materials transport in networks. European Journal of Operational Research, 121, 316-329. 
Figure 1: Hazardous Waste Production and Final Demands in the Economy

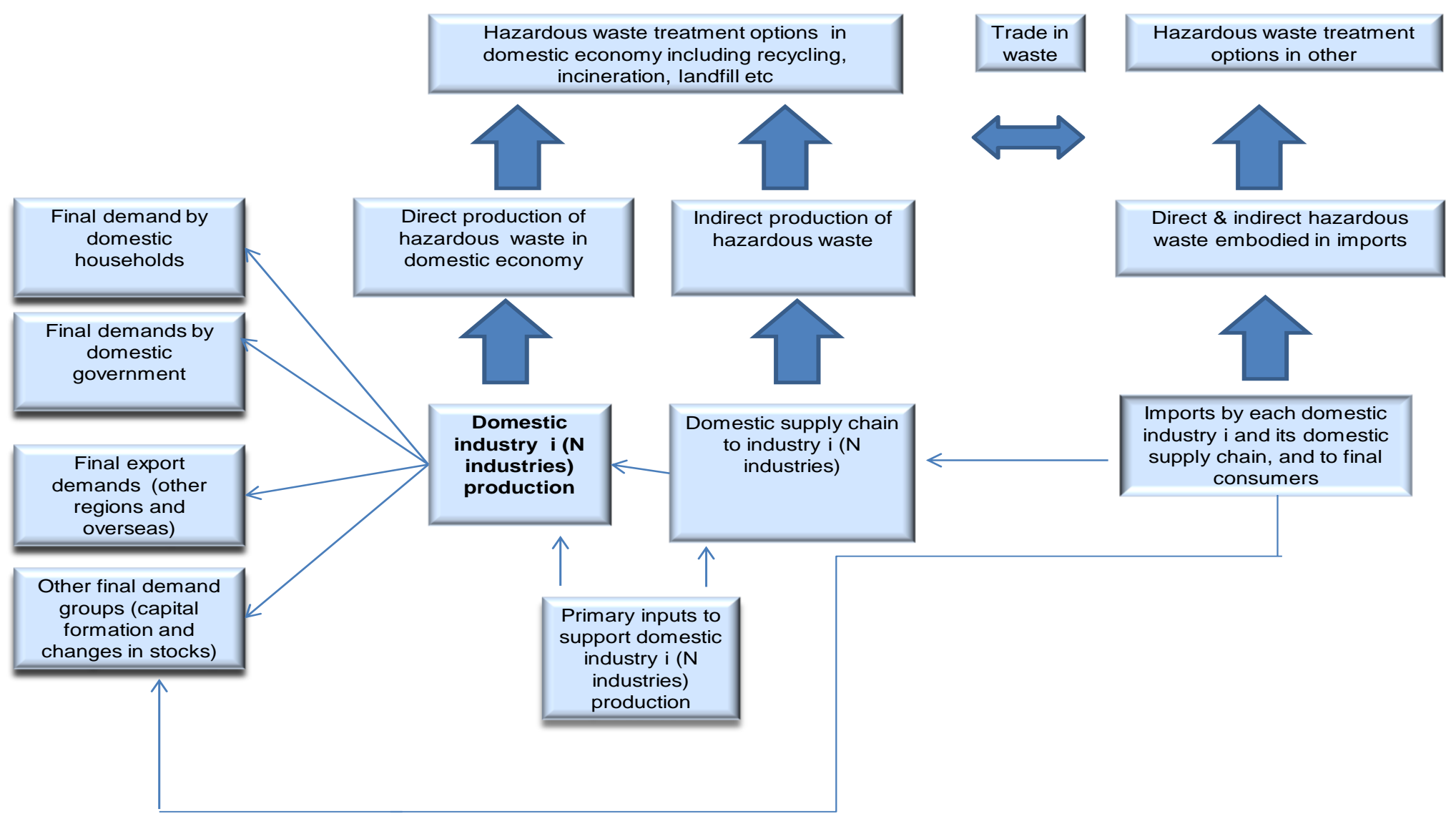


Table 1: Options for Hazardous Waste Management and Disposal

\begin{tabular}{|c|c|}
\hline Management/disposal option & Definitional methods with Option \\
\hline Incineration with energy recovery & $\begin{array}{l}\text { Use of waste principally as a fuel for other } \\
\text { means of electricity generation }\end{array}$ \\
\hline Incineration without energy recovery & Incineration of waste at sea or on land \\
\hline Landfill & $\begin{array}{l}\text { Deep injection, land treatment of waste; } \\
\text { specially engineered landfill; surface } \\
\text { impoundment; tipping above ground }\end{array}$ \\
\hline Recycling/Reuse & $\begin{array}{l}\text { Exchange of wastes that are ultimately } \\
\text { recycled/reused; reclamation or } \\
\text { regeneration of solvents; recovery of } \\
\text { components from catalysts; recycling and } \\
\text { reclamation of metals and metal } \\
\text { compounds; recycling and reclamation of } \\
\text { substances which are not used as solvents; } \\
\text { other inorganic material; regeneration of } \\
\text { acids and bases; re-refining or other uses of } \\
\text { oil which is waste; spreading of waste on } \\
\text { land for agricultural or ecological } \\
\text { improvement; etc. }\end{array}$ \\
\hline Treatment & $\begin{array}{l}\text { Biological treatment; physio-chemical } \\
\text { treatment }\end{array}$ \\
\hline Transfer for disposal & $\begin{array}{l}\text { Blending or mixture of waste prior to } \\
\text { disposal; repackaging of waste prior to } \\
\text { disposal; storage of waste prior to final } \\
\text { disposal }\end{array}$ \\
\hline Transfer for recycling & Storage of waste prior to recycling/reuse \\
\hline Reject & $\begin{array}{l}\text { Rejected bad; rejected by consignees often } \\
\text { due to: unplanned plant and equipment } \\
\text { failure at the consignee's site; planned } \\
\text { closures; environmental conditions and } \\
\text { weather or absence of proper } \\
\text { documentation. }\end{array}$ \\
\hline
\end{tabular}


Table 2. Hazardous waste in the U.K. by generating region and management method ${ }^{6}$

\begin{tabular}{|l|r|r|r|r|}
\hline \multicolumn{1}{|c|}{ Management method } & \multicolumn{1}{c|}{ Wales } & \multicolumn{1}{c|}{ \% } & \multicolumn{1}{c|}{ Rest of UK } & \multicolumn{1}{c|}{ \% } \\
\hline Incineration with energy reco & 571.4 & 0.2 & $207,954.3$ & 3.4 \\
\hline Incineration without energy re & $4,341.8$ & 1.8 & $180,517.8$ & 2.9 \\
\hline Landfill & $29,487.9$ & 12.2 & $823,353.6$ & 13.3 \\
\hline Recycling/reuse & $114,189.0$ & 47.2 & $1,126,744.8$ & 18.3 \\
\hline Rejected & 298.7 & 0.1 & $3,429.2$ & 0.1 \\
\hline Transfer (D) & $16,979.7$ & 7.0 & $374,526.6$ & 6.1 \\
\hline Transfer (R) & $20,826.6$ & 8.6 & $585,598.4$ & 9.5 \\
\hline Treatment & $54,991.4$ & 22.8 & $2,871,280.0$ & 46.5 \\
\hline Total & $\mathbf{2 4 1 , 6 8 6 . 6}$ & $\mathbf{1 0 0 . 0}$ & $\mathbf{6 , 1 7 3 , 4 0 4 . 7}$ & $\mathbf{1 0 0 . 0}$ \\
\hline
\end{tabular}

Table 3 Attribution (\%) of hazardous waste to final consumption group by management option

\begin{tabular}{|l|l|l|}
\hline & $\begin{array}{l}\text { Treatment (\%) } \\
\text { and total) }\end{array}$ & $\begin{array}{l}\text { Landfill (\%) } \\
\text { and total) }\end{array}$ \\
\hline Households & 10.9 & 13.6 \\
\hline Government & 19.8 & 9.7 \\
\hline Stocks & 1.0 & 0.4 \\
\hline Capital formation & 3.3 & 33.7 \\
\hline Tourists & 0.9 & 0.6 \\
\hline Exports RUK & 47.4 & 34.3 \\
\hline Exports Overseas & 16.7 & 7.7 \\
\hline Total 000s tonnes & $\mathbf{5 4 , 9 9 1}$ & $\mathbf{2 9 , 4 8 8}$ \\
\hline
\end{tabular}

${ }^{6}$ Waste is not necessarily managed in the same region that it has been generated in. 
Table 4. Attribution results: hazardous waste for treatment

\begin{tabular}{|c|c|c|c|c|c|c|c|c|c|}
\hline \multirow[b]{2}{*}{ Sector } & \multicolumn{2}{|c|}{ Direct hazardous waste generation } & \multicolumn{2}{|c|}{ Type Imultipliers } & \multicolumn{3}{|c|}{ Breakdown of shift from direct to Type I attribution } & \multicolumn{2}{|c|}{ Type I attrib. to final consumption driver } \\
\hline & $\begin{array}{l}\text { A. Direct intensity } \\
\text { (tonnes per } \\
\text { £1million output) }\end{array}$ & $\begin{array}{c}\text { B. Waste directly } \\
\text { generated in sector } \\
\text { (tonnes and share } \\
\text { of total generated } \\
\text { in Wales) }\end{array}$ & \begin{tabular}{|c|} 
C. Type I output \\
multiplier \\
(£million output all \\
sectors per \\
£1million final \\
demand for \\
sectoral output
\end{tabular} & $\begin{array}{c}\text { D. Type I } \\
\text { hazardous waste } \\
\text { output multplier } \\
\text { (tonnes per } \\
\text { £1million final } \\
\text { demand for } \\
\text { sectoral output) }\end{array}$ & $\begin{array}{c}\text { E Own sector } \\
\text { waste generation to } \\
\text { support own sector } \\
\text { final demand }\end{array}$ & \begin{tabular}{|c|} 
F. Own sector \\
waste generation to \\
support other \\
sector final \\
demand
\end{tabular} & $\begin{array}{c}\text { G. Other sector } \\
\text { waste generation to } \\
\text { support own sector } \\
\text { final demand }\end{array}$ & \begin{tabular}{|c|} 
H. Waste \\
generated in all \\
sectors to support \\
own sector final \\
demand (tonnes \\
and share of total \\
waste generated in \\
Wales): $\underline{\mathrm{B}-\mathrm{F}+\mathrm{G}}$ \\
\end{tabular} & $\begin{array}{c}\text { I. Largest type of } \\
\text { final consumer } \\
\text { supporting } \\
\text { production of } \\
\text { sectoral output and } \\
\text { waste generation } \\
\text { (share supported) }\end{array}$ \\
\hline 17. Oil Processing & 2.319 & $\begin{array}{l}11907 \\
21.7 \% \\
\end{array}$ & 1.151 & 2.400 & 11032 & 875 & 253 & $\begin{array}{r}11285 \\
20.5 \% \\
\end{array}$ & $\begin{array}{r}\text { RUK Exports } \\
67.9 \% \\
\end{array}$ \\
\hline 27. Forging/Pressing & 6.988 & $\begin{array}{r}9143 \\
16.6 \% \\
\end{array}$ & 1.319 & 7.282 & 6276 & 2867 & 101 & $\begin{array}{r}6377 \\
11.6 \% \\
\end{array}$ & $\begin{array}{r}\text { RUK Exports } \\
71.7 \% \\
\end{array}$ \\
\hline 70. Health and Social & 0.996 & $\begin{array}{r}8133 \\
14.8 \% \\
\end{array}$ & 1.543 & 1.456 & 8015 & 118 & 491 & $\begin{array}{r}8506 \\
15.5 \% \\
\end{array}$ & $\begin{array}{r}\text { Welsh Govt } \\
93.0 \% \\
\end{array}$ \\
\hline 72. Sanitary Services & 3.720 & $\begin{array}{l}4698 \\
8.5 \% \\
\end{array}$ & 1.342 & 4.315 & 3708 & 990 & 76 & $\begin{array}{l}3785 \\
6.9 \% \\
\end{array}$ & $\begin{array}{r}\text { Welsh Govt } \\
49.4 \% \\
\end{array}$ \\
\hline 25. Iron and Steel & 0.766 & $\begin{array}{l}2917 \\
5.3 \% \\
\end{array}$ & 1.416 & 0.977 & 2778 & 140 & 577 & $\begin{array}{l}3355 \\
6.1 \% \\
\end{array}$ & $\begin{array}{r}\text { RUK Exports } \\
65.2 \% \\
\end{array}$ \\
\hline All other sectors & & $\begin{array}{l}18202 \\
33.1 \% \\
\end{array}$ & & & & & & $\begin{array}{l}21685 \\
39.4 \% \\
\end{array}$ & \\
\hline
\end{tabular}


Table 5. Attribution results: hazardous waste for landfill

\begin{tabular}{|c|c|c|c|c|c|c|c|c|c|}
\hline \multirow[b]{2}{*}{ Sector } & \multicolumn{2}{|c|}{ Direct hazardous waste generation } & \multicolumn{2}{|c|}{ Type I multipliers } & \multicolumn{3}{|c|}{ Breakdown of shift from direct to Type I attribution } & \multicolumn{2}{|c|}{ Type I attrib. to final consumption driver } \\
\hline & $\begin{array}{l}\text { A. Direct intensity } \\
\text { (tonnes per } \\
\text { £1million output) }\end{array}$ & $\begin{array}{l}\text { B. Waste directly } \\
\text { generated in sector } \\
\text { (tonnes and share } \\
\text { of total generated } \\
\text { in Wales) }\end{array}$ & $\begin{array}{l}\text { C. Type I output } \\
\text { multiplier } \\
\text { (£million output all } \\
\text { sectors per } \\
£ 1 \text { million final } \\
\text { demand for } \\
\text { sectoral output }\end{array}$ & $\begin{array}{c}\text { D. Type I } \\
\text { hazardous waste } \\
\text { output multplier } \\
\text { (tonnes per } \\
\text { £1million final } \\
\text { demand for } \\
\text { sectoral output) }\end{array}$ & $\begin{array}{c}\text { E. Own sector } \\
\text { waste generation to } \\
\text { support own sector } \\
\text { final demand }\end{array}$ & $\begin{array}{c}\text { F. Own sector } \\
\text { waste generation to } \\
\text { support other } \\
\text { sector final } \\
\text { demand }\end{array}$ & $\begin{array}{c}\text { G. Other sector } \\
\text { waste generation to } \\
\text { support own sector } \\
\text { final demand }\end{array}$ & $\begin{array}{c}\text { H. Waste } \\
\text { generated in all } \\
\text { sectors to support } \\
\text { own sector final } \\
\text { demand (tonnes } \\
\text { and share of total } \\
\text { waste generated in } \\
\text { Wales): } \underline{\mathrm{B}-\mathrm{F}+\mathrm{G}} \\
\end{array}$ & \begin{tabular}{|c} 
I. Largest type of \\
final consumer \\
supporting \\
production of \\
sectoral output and \\
waste generation \\
(share supported)
\end{tabular} \\
\hline 45. Construction & 3.532 & $\begin{array}{l}18009 \\
61.1 \% \\
\end{array}$ & 1.466 & 4.237 & 13991 & 4018 & 179 & $\begin{array}{r}14170 \\
48.1 \% \\
\end{array}$ & $\begin{array}{r}\text { Capital formation } \\
68.6 \% \\
\end{array}$ \\
\hline 14. Wood Products & 6.618 & $\begin{array}{r}3256 \\
11.0 \% \\
\end{array}$ & 1.287 & 6.752 & 2615 & 641 & 15 & $\begin{array}{r}2630 \\
8.9 \% \\
\end{array}$ & $\begin{array}{r}\text { RUK Exports } \\
65.3 \% \\
\end{array}$ \\
\hline 72. Sanitary Services & 2.348 & $\begin{array}{r}2965 \\
10.1 \%\end{array}$ & 1.342 & 2.714 & 2341 & 625 & 40 & $\begin{array}{l}2381 \\
8.1 \%\end{array}$ & $\begin{array}{r}\text { Welsh Govt } \\
49.4 \%\end{array}$ \\
\hline $\begin{array}{l}\text { 59. Real estate, ownership } \\
\text { rental of dwellings }\end{array}$ & 0.002 & $\begin{array}{r}16 \\
0.1 \% \\
\end{array}$ & 1.138 & 0.211 & 15 & 1 & 1395 & $\begin{array}{r}1410 \\
4.8 \% \\
\end{array}$ & $\begin{array}{r}\text { Welsh Households } \\
78.4 \% \\
\end{array}$ \\
\hline 68. Public admin & 0.007 & $\begin{array}{r}46 \\
0.2 \% \\
\end{array}$ & 1.309 & 0.202 & 45 & 1 & 1218 & $\begin{array}{r}1263 \\
4.3 \% \\
\end{array}$ & $\begin{array}{r}\text { Welsh Govt } \\
93.8 \% \\
\end{array}$ \\
\hline All other sectors & & $\begin{array}{r}5195 \\
17.6 \%\end{array}$ & & & & & & $\begin{array}{r}7635 \\
25.9 \%\end{array}$ & \\
\hline
\end{tabular}


Appendix. The 73 Sectors Identified in the Welsh Input-Output Tables

\begin{tabular}{|c|c|c|}
\hline Sector \# & Sector Name & SIC (2003) Mapping \\
\hline 1 & Agriculture and fish & 01,05 \\
\hline 2 & Forestry & 02 \\
\hline 3 & Coal and other primary extraction & $10,11,12$ \\
\hline 4 & Other mining and quarrying & 13,14 \\
\hline 5 & Meat & $15.1,15.4$ \\
\hline 6 & Dairy & 15.5 \\
\hline 7 & Fish products, vegetables, and grain mill products & $15.2,15.3,15.6$ \\
\hline 8 & Bread and biscuits & $15.81,15.82$ \\
\hline 9 & Miscellaneous foods & $15.71,15.72,15.85-15.89$ \\
\hline 10 & Confectionery & $15.83,15.84$ \\
\hline 11 & Drinks and tobacco & $15.91-15.98,16.00$ \\
\hline 12 & Textiles & $17.1-17.7$ \\
\hline 13 & Clothing & $18.1-18.3,19.1-19.3$ \\
\hline 14 & Wood products & 20 \\
\hline 15 & Paper and pulps & $21.1,21.2$ \\
\hline 16 & Publishing & 22 \\
\hline 17 & Oil processing & 23 \\
\hline 18 & Chemicals & $24.1-24.3,24.6,24.7$ \\
\hline 19 & Pharmaceutical & 24.4 \\
\hline 20 & Soaps & 24.5 \\
\hline 21 & Rubber products & 25.1 \\
\hline 22 & Plastics & 25.2 \\
\hline 23 & Glass and ceramics & $26.1-26.3$ \\
\hline 24 & Cement and plaster & $26.4-26.8$ \\
\hline 25 & Iron and steel & $27.1-27.3$ \\
\hline 26 & Aluminium and non-ferrous metals & $27.41-27.45$ \\
\hline 27 & Forging and pressing & $27.5,28.4-28.7$ \\
\hline 28 & Structural metals & $28.1-28.3$ \\
\hline 29 & Machinery & $29.1-29.6$ \\
\hline 30 & Domestic appliances & 29.7 \\
\hline 31 & Office machinery & 30 \\
\hline 32 & Electrical motors and transformers & $31.1,31.2$ \\
\hline 33 & Wires and cables & 31.3 \\
\hline 34 & Industrial electrical equipment & $31.4-31.6$ \\
\hline 35 & Electronic components & $32.1,32.2$ \\
\hline 36 & Televisions & 32.3 \\
\hline 37 & Control equipment & 33 \\
\hline 38 & Motor vehicles & 34 \\
\hline 39 & Other vehicles & 35 \\
\hline 40 & Furniture & 36.1 \\
\hline 41 & Other manufacturing & $36.2-36.6,37.1,37.2$ \\
\hline 42 & Electricity & 40.1 \\
\hline 43 & Gas & $40.2,40.3$ \\
\hline 44 & Water & 41 \\
\hline 45 & Construction & 45 \\
\hline 46 & Distribution and repairs & 50 \\
\hline 47 & Wholesale & 51 \\
\hline 48 & Retail & 52 \\
\hline 49 & Accomodation and restaurants & 55 \\
\hline 50 & Railways & 60.1 \\
\hline 51 & Road transport & $60.2,60.3$ \\
\hline 52 & Sea and air transport & 61,62 \\
\hline 53 & Transport services and travel agents & 63 \\
\hline 54 & Postal services & 64.1 \\
\hline 55 & Telecommunications & 64.2 \\
\hline 56 & Banking and finance & 65 \\
\hline 57 & Insurance & 66 \\
\hline 58 & Other financial services & 67 \\
\hline 59 & Real estate and ownership and rental of dwellings & 70 \\
\hline 60 & Renting of moveables & 71 \\
\hline 61 & Legal services & 74.11 \\
\hline 62 & Accountancy services & 74.12 \\
\hline 63 & Computer and related activities & 72 \\
\hline 64 & Research and development & 73 \\
\hline 65 & Market research and advertising & $74.13-74.15,74.40$ \\
\hline 66 & Other business services & $74.5-74.8$ \\
\hline 67 & Other professional services & $74.2-74.3$ \\
\hline 68 & Public administration & 75 \\
\hline 69 & Education & 80 \\
\hline 70 & Health and social work & $85.1-85.3$ \\
\hline 71 & Recreation & 92 \\
\hline 72 & Sanitary services & 90 \\
\hline 73 & Other services & $91,93,95-97,99$ \\
\hline
\end{tabular}




\section{Can Hazardous Waste Supply Chain 'Hotspots' be Identified using an Input-Output Framework}

\section{Reviewer 1 Response}

We are grateful for the comments of the Reviewer. Below we have restated the elements of the comments that require action and then in italics how we have sought to deal with the issue in the revised paper.

1.1. Although an interesting piece of work on an important topic there was a need to improve the presentation and discussion of the results. The manuscript was also wordy and with scope to reduce Section 3 , 4, and 5

We have revised each of the sections of the paper. Section 1 is now shorter and comes more quickly to the purpose of the paper and its structure. In section 2 we have removed much of the material relating to regulatory issues but added some material to better restate the nature of the problem we are studying, and added a Figure to illustrate the problem. Section 3 has been reduced in size to focus on core elements of the method, with (as in the initial submission) just a brief overview of how we move to the Welsh case study in Section 3.3, before proceeding to full discussion of data and results in Section 4. However, in Section 4 in particular we have been more concise in the presentation of the main findings (sub sections 4.2 and 4.3). We then relate the findings more to their practical use by policy makers and other stakeholders concerned about the levels of hazardous waste produced and their treatment: we have developed a new sub section 4.4 to deal with the practical issues deriving from the analysis). We have reduced the size of the paper overall and it remains within the stated advised limits for the journal.

1.2. Reviewer 1 noted that there were other sources that cover the methodological framework more effectively, and the paper needs to relate theory to the empirical analysis more concretely.

As noted, we have reduced and focused the method section. In doing, so we have revisited the literature review and enhanced the references to highlight those that cover the methods framework more effectively. There have also been some revisions to the presentation of the core methods in Section 3, particularly in sub section 3.2. We have moved some of the material that was in Section 4 spelling out the application of the method (but made this much shorter, more concise and generic - see $p 9$ ). We hope that this means the reader will have a clear expectation of what is coming. Moreover, it means that we have been able to make the discussion of results more concise with clear referencing back to relevant steps in the method in Section 3.

\section{Reviewer 2 Response}

We are grateful for the comments of the Reviewer. Below we have restated the elements of the comments that require action and then in italics how we have sought to deal with the issue in the revised paper.

2.1. Issue that the first two sections of the paper essentially discussed regulatory requirements. While it was important and necessary to emphasize the need for the research the Reviewer felt this discussion was too long. This issue of wordiness was also commented on by Reviewer 1 .

We have revised Sections 1 and 2. The introduction is now shorter and focuses on what the paper does, and with the background shortened. In Section 2 we have reduced the material that deals with the various rules and regulations leaving in the references, so that the reader can check these as required. However, we have revised section 2 to better present the waste generation process (see point 2.2 below). In relation to the point on wordiness we have tried to edit down the paper throughout, albeit with the need to add a short sub section to Section 4 (the new sub-section 4.4. - see below).

2.2. Issue that although regulatory requirements were discussed at length, the waste generation process and its relation to management options was not discussed systematically i.e. the problem definition was not given. The Reviewer noted that some explanations on the process and items such as treatment options were vague until section 4 and suggested a figure similar might help to explain the system. 
We have reduced the discussion of regulatory requirements in Section 2, and have in the revision improved the discussion of the problem and added a diagram (Figure 1) showing the links between final consumption, industrial production, and defined treatment options. In doing we also have taken some material from section 4 which the referee shows comes too late in the paper (i.e. relating to what hazardous waste is, and the definition of treatment options (Table 1) and integrated this into the background Section 2.

2.3 Issue that the paper claims to extend the conventional demand-driven input-output attribution methods while main contribution was in decomposing the matrix and need to clarify the methodological contribution.

We have clarified the nature of the contribution in the abstract (where we say "It extends application of conventional demand driven input-output attribution methods to identify hazardous waste 'hotspots' in the supply chains of different final consumption goods and consumption groups") and in Section 3.1, third paragraph (before we detail the specific elements of the input-output method that are used in Section 3.2). What we have shown here is that we are not claiming to develop new methodology; rather seeking to develop a novel application from the method i.e. showing that with some modification to exploit the potential for decomposing results, how the established method can be applied to a regional problem providing useful material for decision makers. We believe that there is limited material focusing on the decision making support that can be provided by detailed decompositions within the framework. To this end we have now also improved material in Section 4 that treats with how this approach can assist decisions (see point 2.6 below).

2.4. In Section 3 dealing with method the paper stated the number of rows and columns in several parts of the paper by referring forward to the analysis part.

This relates to other points made by Reviewer 1 and 2 that have led to us shortening the method section and reorganizing material between Sections 3 and 4. In the revised paper we have removed reference to the number of rows and columns (i.e. number of industries, final consumption groups, and management options) from the core method section 3.2 and now do not mention the number of final demand, industries and management options until we move to the consideration of the specific information we have used in developing the case in 3.3 .

2.5. In section 3 the initial version of the paper had provided the first 3 equations and then, before giving the fourth equation, explained in parentheses the notation used.

Our method section now starts with what was equation [5] where the statement referred to here was made. Now equation [5] becomes equation [1] and the explanation of notation is given immediately after equation [1] on p.7.

2.6. Issue that section 4 was too long and verbose, and with the need to explain how to read and interpret the tables on an example and then to emphasize the insights for the decision makers. There the Reviewer states that we need to be focus more on how results could be synthesized and what they mean for decision makers. Moreover, the reviewer notes that it is stated in several parts how certain results are obtained (e.g., by multiplying which row by which column) and this better belongs in the methods section.

As noted above, we have revised section 4 so as not to conflate with material that is in the methods section. We have removed some of the more detailed material relating to how results are derived as this is now treated in the revised section 3 (see response to point 1.2 of the first reviewer and p. 9 of the revised text). We have pared the discussion down but have added a new sub section 4.5 that shows why selected material in Tables 3-5 is of particular interest to decision makers. In summary, we have tightened up the discussion of results in Sections 4.2 and 4.3, removing clarification of the method there and making it part of the discussion in Section 3, but, as noted above, have added a new Section 4.4 discussing the potential importance to decision makers. 
2.7. The Reviewer notes that findings were valuable for policy makers but argues that, considering the contribution with respect to methodology and how the results are reported, the paper may be suitable for a journal with a focus on regional sciences etc.

It is accepted that the case material relates to a UK region. However, we believe that the application of inputoutput methods, the focus on supply chains, and the role of the type of analysis presented in informing decisions means that it is better situated in journals such as EJOR. Moreover, in line with comments of Reviewers 2 and 4 we have attempted to relate our findings in the revision more in terms of how they might help decision makers in the revised Section 4.

\section{Reviewer 3 Response}

We are grateful for the comments of the Reviewer who noted that the article is written well and provided a supporting reasoning for motive and methodology. For the information of Reviewer 3 we have tried to further improve the presentation of the paper in the revision.

\section{Reviewer 4 Response}

We are grateful for the comments of the referee. Below we have summarized the central comment and then in italics how we have sought to deal with the issue in the revised paper.

4.1 Reviewer 4 highlighted several strengths of the manuscript relating to clarity, review, references, and method but was concerned about the lack of discussion of real world circumstances.

This comment linked to those of Reviewer 2 and we have in the revision improved Section 4 by reducing some of the more technical discussion of results, but then highlighted more how the material would be relevant for decision makers in the real world in sub section 4.4. 